\title{
Theoretical Modeling of the Possibility of Acid Producing Bacteria Causing Fast Pitting Biocorrosion
}

Tingyue Gu*

Department of Chemical and Biomolecular Engineering, Institute for Corrosion and Multiphase Technology, Ohio University, Athens, Ohio, USA

\begin{abstract}
Biocorrosion, also known as microbiologically influenced corrosion (MIC), is caused by various corrosive biofilms. So far, laboratory experimental MIC pitting tests in the published literature have overwhelmingly focused on sulfate reducing bacteria (SRB) that use sulfate as the terminal electron acceptor because SRB and sulfate are often found at anaerobic pitting sites. Many laboratory pure-culture SRB pitting corrosion data have been reported and they are often less than or not much greater than $1 \mathrm{~mm} /$ year. There are also some limited data available for nitrate reducing bacteria (NRB) that use nitrate or nitrite as the terminal electron acceptor. Dedicated laboratory studies are lacking on anaerobic corrosion by acid producing bacteria (APB) that undergo anaerobic fermentation instead of anaerobic respiration in the absence of an external terminal electron acceptor such as sulfate and nitrate. Failures in pipelines carrying crude oil and produced water purportedly due to MIC have been reported in the literature. Some point to very high pitting corrosion rates (as high as $10 \mathrm{~mm} / \mathrm{year}$ ) that are much higher than the short-term laboratory MIC pitting corrosion rates for SRB. The pipeline failure cases discussed in this work occurred in relatively low sulfate conditions. This work explored the possibility of very high MIC pitting corrosion rates due to free organic acids (represented by acetic acid) and acidic $\mathrm{pH}$ corrosion through mechanistic modeling to show that APB biofilms are capable of very fast MIC pitting while mass transfer limitation on sulfate diffusion from the bulk-fluid phase to the biofilm cannot support very fast pitting caused by sulfate reduction in a low sulfate concentration environment. More efforts should be devoted to MIC by APB instead of focusing too much on SRB.
\end{abstract}

Keywords: APB; SRB; MIC; Mechanistic model; Pipeline corrosion; Biofilm

\section{Introduction}

It is widely accepted that biocorrosion accounts for $20 \%$ of all corrosion losses. It is also known as microbiologically influenced corrosion (MIC). In recent years, MIC has become an increasingly important problem in the oil and gas industry since the Alaska pipeline leak in the spring of 2006 that caused a major disruption of US oil production. MIC was a major suspect in that incident [1]. Sulfate reducing bacteria (SRB) are often blamed for MIC, primarily because of their frequent presence at corrosion sites in corrosion cases that are believed to be MIC related [2]. Acid producing bacteria (APB) have also been known to be involved in MIC. However, the overwhelming majority of MIC literature and laboratory investigations were focused on SRB, leading to the misconception that APB play only a minor role in MIC. MIC forensics is poorly practiced at present compared to the stringent pathogen identification in the medical field that relies on the very methodical Koch's postulates [3]. The presence of a microbe at a corrosion site does not automatically prove its culpability because microbes are everywhere under field conditions. SRB are ubiquitous in nonsterile environments that have sulfate. Published MIC field cases [4-6] often depended on a process of elimination to narrow down the suspect to MIC without any convincing direct evidence, sometimes by relying on a general belief that conventional chemical corrosion tends to have a far more uniform environment. Thus, pipeline failures involving only one or a few large pits in a long pipe section were believed likely due to MIC because biofilm formation was opportunistic. This uncertainty necessitates laboratory MIC testing with defined microbiological conditions to provide clues.

It is well known that biofilms causes MIC due to their metabolic activities or secreted metabolites. There are two distinct types of anaerobic metabolism [7]. The first type is anaerobic respiration in which an external (non-oxygen) oxidant such as sulfate, thiosulfate, sulfite, sulfur, nitrate, nitrite, $\mathrm{CO}_{2}$, etc. serves as the terminal electron acceptor to adsorb the electrons released from organic carbon oxidation (or hydrogen oxidation by methanogens and some SRB among others). The electron transport chain in anaerobic respiration provides energy for ATP (an energy-storage molecule) synthesis. In laboratory culturing of SRB, lactate is often used as the electron donor and sulfate as the terminal electron acceptor to provide energy needed for SRB growth. Xu et al. [8] showed that starting with the same mature Desulfovibrio vulgaris (ATCC 7757) biofilms, when the SRB biofilms were subsequently starved of organic carbon, this SRB pitted carbon steel more aggressively. This suggested that some sessile SRB cells switched from organic carbon oxidation to iron oxidation, i.e., oxidation of elemental iron $\mathrm{Fe}(0)$ to ferrous $\mathrm{Fe}(\mathrm{II})$ ion. In the absence of an organic carbon and other electron donors (such as $\mathrm{H}_{2}$ ), elemental iron becomes a substitute fuel for energy production [7]. Unlike lactate oxidation, iron oxidation does not produce any organic carbons that can be used in organic synthesis needed for growth. Thus, iron is merely a fuel rather than food for SRB. SRB do not "eat" iron, but they extract energy from it by coupling its oxidation with sulfate reduction. Energy is always needed by microbes because even when they are not growing their survival requires the so-called maintenance energy [7].

*Corresponding author: Prof. Tingyue Gu, Department of Chemical and Biomolecular Engineering, Institute for Corrosion and Multiphase Technology, Stocker Center 167B, Ohio University, Athens, Ohio 45701, Ohio, USA, Tel: 740593-1499; Fax: 740-593-0873; E-mail: gu@ohio.edu

Received December 24, 2013; Accepted January 21, 2014; Published January 24,2014

Citation: Gu T (2014) Theoretical Modeling of the Possibility of Acid Producing Bacteria Causing Fast Pitting Bioc'orrosion. J Microb Biochem Technol 6: 067-073. doi:10.4172/1948-5948.1000124

Copyright: (c) $2014 \mathrm{Gu}$ T. This is an open-access article distributed under the terms of the Creative Commons Attribution License, which permits unrestricted use, distribution, and reproduction in any medium, provided the original author and source are credited 
The second type of anaerobic metabolism is anaerobic fermentation. In the absence of an external electron acceptor, fermentative microbes such as APB and certain SRB strains that are capable of fermentative growth oxidize an organic carbon and produce ATPs through substrate-level phosphorylation. No external electron acceptors are required because cells achieve the redox balance by producing their own electron acceptors that are organic carbons derived from the carbon source. Anaerobic fermentation products typically are organic acids such as volatile fatty acids (lactic acid, acetic acid or HAc, etc.) and alcohols, etc. [7]. Due to organic acid production, the $\mathrm{pH}$ underneath an APB biofilm can be considerably lower than the bulk-fluid $\mathrm{pH}$. It is said that the $\mathrm{pH}$ differential between the bulk-fluid and the bottom of a biofilm can be greater than 2. Vroom et al. [9] located an area with $\mathrm{pH}<3$ in a biofilm adjacent to areas with $\mathrm{pH}>5$ using the two-photon excitation microscopy technique. Some APB can produce alarmingly large amounts of organic acids. Pope et al. [10] found that the broth of a mixed-culture APB "contained organic acids totaling 12,000 ppm. Acetic acid was at $4000 \mathrm{ppm}$ ". They did not explicitly indicate broth $\mathrm{pH}$ and whether these were free (undissociated) acid concentrations or not. The concentrations were very likely total concentrations including free acids and dissociated acids because their data came from ion chromatography that could not distinguish them.

The acidity in an APB broth is caused by the protons released by the organic acids. Because these organic acids are weak acids, the majority of them are still in the free acid form. They are corrosive because the reduction of the protons and free acids combined with iron oxidation is thermodynamically favorable and kinetically not retarded. They are a serious threat because the free organic acid concentrations can be much higher than proton concentrations. Their corrosive ability dwarfs that of protons due to their much higher concentrations compared with proton concentrations. For example, a pH 2 acetic acid solution is much more corrosive than a $\mathrm{pH} 2$ sulfuric acid solution [10]. The acetic acid solution at $\mathrm{pH} 2$ contains a very large free acetic acid concentration while the $\mathrm{pH} 2$ sulfuric acid solution contains no undissociated sulfuric acid in the liquid because sulfuric acid is a very strong acid. The free acetic acid can serve as a reservoir to re-supply protons that are consumed by corrosion.

Bhat et al. [4] discussed the failure of a new 8-inch ID pipe $(6.4 \mathrm{~mm}$ wall thickness) that failed in only 8 months at $45^{\circ} \mathrm{C}$, corresponding to an averaged pitting corrosion rate of $9.6 \mathrm{~mm} /$ year assuming no initial delay in the onset of the corrosion. The untreated pipeline carried oil and produced water (as high as $70 \%$ water-cut) at $\mathrm{pH}$ 5.1. Both APB and SRB were found to be present in the pipeline fluid that contained $1500 \mathrm{ppm}$ acetic acid and no detectable sulfate. Samant et al. [5] reported that an offshore 16-inch ID (22.2 mm thickness) pipeline carrying well fluid (oil/gas/water) failed in 2.5 years at $41^{\circ} \mathrm{C}$ very likely due to MIC. In this case, the pitting corrosion rate averaged $8.9 \mathrm{~mm} /$ year. The pipeline fluid contained $410 \mathrm{ppm}$ sulfate with a water-cut of $75 \%$. In both cases above, the roughly 4 psi $\mathrm{CO}_{2}$ partial pressure could not account for the severe corrosion rate. DuBose et al. [6] investigated the well-known 1991 Lost Hills, CA oil and water gathering system MIC failure that occurred 18 months after startup with an averaged pitting corrosion rate of $6.8 \mathrm{~mm} /$ year. Coupon tests in the pipeline showed that the coupons suffered no pitting in the first month, but a $7.6 \mathrm{~mm} /$ year pitting corrosion rate was observed in the second month. No corrosion of coupons in turbulent areas occurred, suggesting that $\mathrm{CO}_{2}$ corrosion could not be a factor. All the three cases above involved constant water-wetting condition and no oxygen. These conditions were favorable for anaerobic microbial biofilms to thrive in the presence of organic nutrients. The constant water-wetting condition allows a much larger variety of microbes to flourish than the oil-wetting or the intermittent water-wetting condition, thus increasing the possibility of a very corrosive biofilm on the pipe wall. As water-flooding is more frequently used to increase well pressure in older wells, water-wetting condition for an oil transport pipeline is becoming more common than ever. The risk for fast MIC pitting failure is undoubtedly heightened.

This work showed that these very fast purported MIC pitting corrosion rates could not be accounted for by SRB pitting alone because in these systems with zero or a low sulfate concentration, sulfate diffusion from the bulk- fluid phase to the biofilm was far from sufficient to sustain the high MIC pitting corrosion rates. APB could be the primary suspect in this kind of fast anaerobic MIC pitting failures.

\section{Mechanistic Modeling of MIC Due to SRB and APB}

Gu et al. [11] proposed a new theory called Biocatalytic Cathodic Sulfate Reduction (BCSR) theory based on bioenergetics. They departed from the tradition of corrosion engineers who searched for a physical anode and a cathode when studying MIC mechanisms. Instead, they suggested that MIC by SRB is due to the utilization of electrons from iron oxidation by sulfate reduction in SRB cells as shown below,

$$
\begin{aligned}
& \mathrm{Fe} \rightarrow \mathrm{Fe}^{2+}+2 \mathrm{e}^{-} \\
& \mathrm{SO}_{4}^{2-}+9 \mathrm{H}^{+}+8 \mathrm{e}^{-} \rightarrow \mathrm{HS}^{-}+4 \mathrm{H}_{2} \mathrm{O}
\end{aligned}
$$

This electron utilization process requires the biocatalysis of an SRB biofilm for sulfate reduction. Instead of a physical anode and a cathode, they proposed that an anodic reaction (iron oxidation) and a cathodic reaction (sulfate reduction) together cause MIC. The word "cathodic" here overlaps with the word "reduction," both indicating that the half reaction is an electron utilization reaction. The use of "cathodic" is only for easier understanding by corrosion engineers. Reaction (2) actually happens in the cytoplasm inside SRB cells [12] while Reaction (1) happens outside SRB cells. There is no physical cathode, but rather sulfate reduction reaction in the cytoplasm. Reaction (2) should not be interpreted as reducing the acidity of an $\mathrm{SRB}$ culture. The actual reactions are far more complicated. Proton is present in the equation to balance the half reaction stoichiometrically. Elemental iron is considered the electron donor while sulfate is the terminal electron acceptor for sulfate respiration. The combined redox reaction is thermodynamically favorable (energy producing), but sulfate reduction is kinetically retarded by a high activation energy unless there is biofilm catalysis. Reaction (1) does not require biocatalysis, but it won't proceed if Reaction (2) is blocked. In lab tests, a polished carbon steel coupon in a deoxygenated SRB culture medium remains unpitted and shiny unless an SRB seed culture is introduced. Iron oxidation occurs beneath an SRB biofilm and it supplies electrons to the biofilm for sulfate reduction either directly or indirectly. The various direct and indirect cross-cell wall electron transfer methods between a metal surface and a biofilm in MIC was recently discussed by $\mathrm{Gu}$ [13]. Direct update of electrons from an electrode has even seen applications in microbial electro-synthesis to produce useful chemicals using biofilms [14]. Various methods of electron transfer are also discussed extensively in the literature of microbial fuel cells [15], although in most cases, the electron transfer direction is from inside the anodic biofilm cells to the electrode outside with the exception of biocathodes [16]. Iron oxidation can also couple with water or proton reduction to produce $\mathrm{H}_{2}$ (just as in chemical corrosion without biocatalysis of a biofilm). $\mathrm{H}_{2}$ is well known as an electron donor that 
can be used as an energy source for culturing hydrogenase-positive SRB. SRB cells benefit from the thermodynamically favorable redox reaction (oxidation of $\mathrm{H}_{2}$ coupled with sulfate reduction) because energy is produced. This is just one example among several different mechanisms for SRB to transport electrons from outside the cells to the cytoplasm. This example is consistent with the classic cathodic depolarization theory (CDT) $[17,18]$ that is valid for hydrogenasepositive SRB. When the local SRB cells on an iron surface in a biofilm are starved of organic carbon due to a lack of organic carbon in the bulk-fluid phase or due to diffusional limitation, the cells will switch from organic carbon oxidation to iron oxidation to obtain maintenance energy for survival [7]. In fact, $\mathrm{Fe}(0)$, or strictly speaking $\mathrm{Fe}^{2+} / \mathrm{Fe}(0)$, has a standard potential of $-447 \mathrm{mV}$ that is close to the $-430 \mathrm{mV}$ standard potential of lactate at $\mathrm{pH} 7$ and $25^{\circ} \mathrm{C}$. Lactate is often a favored organic carbon for SRB in lab tests. Both potentials are more negative than the $-217 \mathrm{mV}$ standard potential for sulfate reduction [19]. This means both iron oxidation and lactate oxidation can donate electrons for sulfate reduction with concomitant energy production. All potentials in this work are relative to the standard hydrogen potential.

Although other SRB MIC mechanisms have been proposed such as the cathodic FeS film corrosion theory [20], it is undisputed in SRB bioenergetics that sulfate acts as the terminal electron acceptor [21]. This means electrons released by iron oxidation are ultimately absorbed by sulfate reduction in the cytoplasm of the SRB cells. The iron sulfide film beneath an SRB biofilm is not an electron sink. It's in the path of electron transport route from iron surface to the biofilm. Different forms of iron sulfide have different abilities to transport the electrons across the iron sulfide mineral film. It is well known that Mackinawite passivates the iron surface against corrosion. If an iron sulfide film allows electrons to pass through it into the SRB biofilm, MIC can occur.

NRB have also been found to be corrosive. Xu et al. [22] reported that Bacillus licheniformis, a ubiquitous bacterium that is also found in oil field biofilm consortia, pits more aggressively in their lab experiments than typical SRB. This means nitrate injection in reservoir souring mitigation should be metered carefully to avoid unspent nitrate in the transport lines, which can serve as the terminal electron acceptor for MIC. The BCSR theory can be readily extended to the Biocatalytic Cathodic Nitrate Reduction (BCNR) theory for nitrate reducing bacteria (NRB) that respire on nitrate. If the end product for nitrate reduction is nitrogen, the cathodic reaction is written as follows.

$$
2 \mathrm{NO}_{3}^{-}+12 \mathrm{H}^{+}+10 \mathrm{e}^{-} \rightarrow \mathrm{N}_{2}+6 \mathrm{H}_{2} \mathrm{O}
$$

Reaction (3) has a standard potential of $+760 \mathrm{mV}$, much more positive than that of sulfate reduction [19]. This means NRB MIC has a much larger thermodynamic driving force than SRB MIC. Fortunately, nitrate is not typically present at a significant concentration in systems not involving nitrate injection for souring control or water contaminated with agricultural run-off.

Instead of using the term SRB, Xu et al. [8] suggested a more general term XRB (X reducing bugs including methanogens that are archaea) where $\mathrm{X}$ stands for any non-oxygen oxidant such as sulfate, nitrate, nitrite, sulfur, $\mathrm{CO}_{2}$, etc. Thus, the MIC theory can be generalized as Biocatalytic Cathodic X Reduction (BCXR) theory that is suitable for MIC due to anaerobic respiration. When the BCXR mechanism is involved in MIC, the motive for the XRB is to harvest energy and the attack on iron is "intentional," requiring active biofilm catalysis for the reduction reaction (e.g., sulfate reduction). This means the microbe will deliberately maintain the enzyme levels for the MIC process because of the energy payback. This is known as Type I MIC mechanism that has a direct bioenergetic benefit to the biofilm [22]. The Type II MIC mechanism is the attack by secreted metabolites such as organic acids. It is possible that microbes do not directly benefit bioenergetically because the thermodynamically favorable redox reaction (iron oxidation coupled with acid or proton reduction) occurs outside cells without any need for biocatalysis. One possible exception is the utilization of $\mathrm{H}_{2}$ (a corrosion product from proton or organic acid reduction when coupled with iron oxidation) by methanogens and some SRB species. In such a case, it cannot be ruled out that cells actively push the corrosion forward for their own gain because these sessile cells in the biofilm can benefit from the production of the energy molecule $\left(\mathrm{H}_{2}\right)$. Thus, in this case Type II mechanism can also be intentional.

Apart from the primary example of Type II MIC attack due to oxidants secreted by anaerobic fermentation (e.g., organic acids secreted by APB). Corrosion by exopolymeric substances (EPS) also belongs to this type. Oxidants such as uronic acids in EPS may be directly responsible for MIC [23]. An exception is the case that EPS left behind after the cells are killed can still cause MIC due to cell-free enzyme catalysis [24]. However, this may be an insignificant carryover case from Type I. Due to a lack of living cells, this kind of Type I MIC will cause only limited damages because the dead biomass will eventually lose enzyme activities or lose a direct contact (required for electron transfer) with a pit bottom surface as the pit grows deeper. Copper corrosion by SRB belongs to Type II rather than Type I MIC. Unlike the $\mathrm{Fe}^{2+} / \mathrm{Fe}$ standard potential $(-447 \mathrm{mV})$, the $\mathrm{Cu}^{2+} / \mathrm{Cu}$ and $\mathrm{Cu}^{+} / \mathrm{Cu}$ standard potentials $(342 \mathrm{mV}$ and $521 \mathrm{mV})$ are much more positive such that direct $\mathrm{Cu}$ oxidation to $\mathrm{Cu}^{2+}$ or $\mathrm{Cu}^{+}$ion will not happen. Coupling copper oxidation with sulfate reduction is not thermodynamically favorable. However, the direct reaction of copper with $\mathrm{H}_{2} \mathrm{~S}$, a metabolite secreted by SRB, is thermodynamically favorable and requires no biocatalysis. MIC mechanisms other than Types I and II are also possible. For example, Type III MIC may be defined for (secreted) enzyme attacks on organic materials such as polymer pipes. Microbes utilize the small organic molecules from the corrosion process as organic carbon for metabolism. This kind of corrosion is better known as biodegradation.

The effect of acetic acid (HAc) on $\mathrm{CO}_{2}$ chemical corrosion was studied by George et al. [25]. They obtained a corrosion rate close to $10 \mathrm{~mm} /$ year for X65 carbon steel (a common pipeline steel) at $40^{\circ} \mathrm{C}$ and $\mathrm{pH} 4$ with $100 \mathrm{ppm}$ total acetates (HAc and $\mathrm{Ac}^{-}$combined) in the bulk liquid with bubbling $\mathrm{CO}_{2}$ in a rotating cylinder $(1000 \mathrm{rpm})$ glass cell. APB can secrete various organic acids. In practice, these organic acids are often expressed as HAc equivalent because it is impractical to account for all the organic acids individually. HAc is a weak acid. Its disassociation to acetate ion and proton is reversible,

$\mathrm{HAc} \leftrightarrows \mathrm{H}^{+}+\mathrm{Ac}^{-}$

The molar concentration-based equilibrium constant for this reaction is,

$$
\mathrm{K}_{\mathrm{a}}=\frac{\left[\mathrm{H}^{+}\right]\left[\mathrm{Ac}^{-}\right]}{[\mathrm{HAc}]}
$$

in which $\mathrm{K}_{\mathrm{a}}$ is a function of absolute temperature $\mathrm{T}$ in Kelvin [26],

$$
\mathrm{K}_{\mathrm{a}}=10^{-6.66104+0.0134916 \mathrm{~T}-0.0000237856 \mathrm{~T}^{2}}
$$

If consumed protons are re-supplied by Reaction (4) during the course of corrosion, the concentration of noncorrosive Ac can increase 
greatly. On the other hand, if some protons are from other sources, Ac concentrations will be lower. [Ac] can come from sources other than Reaction (4), and its value impacts the availability of undissociated HAc that is corrosive.

Both proton and undissociated HAc can be reduced to accept electrons from iron oxidation [27],

$$
2 \mathrm{H}^{+}+2 \mathrm{e}^{-} \rightarrow \mathrm{H}_{2} \text { (Proton reduction) }
$$

$2 \mathrm{HAc}+2 \mathrm{e}^{-} \rightarrow 2 \mathrm{Ac}^{-}+\mathrm{H}_{2}$ (Free acetic acid reduction)

Because Reaction (4) is extremely fast, it is not possible to distinguish the reduction of HAc from the reduction of proton according to Garsany et al. [28]. This means HAc behaves like a proton reservoir that releases protons on demand for proton reduction. For simplicity in APB MIC modeling in this work, it was assumed that acidity underneath the biofilm is solely due to the dissociation of HAc. Apart from APB, some SRB can also produce small amounts of organic acids if these SRB are present in the biofilm consortium. Because HAc is a weak acid, $[\mathrm{HAc}]$ is usually far larger than $\left[\mathrm{H}^{+}\right]$. Thus, iron oxidation due to HAc reduction is far more severe than proton reduction [25].

Both charge transfer resistance and mass transfer resistance are considered in the BCSR model [11]. The charge transfer resistance 1/ ict can be obtained using the Butler-Volmer equation below that treats all half reactions such as Reactions (1) and (2) as reversible reactions,

$$
\begin{aligned}
\mathrm{i}= & \mathrm{i}_{0} \cdot\left\{\exp \left[\frac{(1-\alpha) \cdot \mathrm{n} \cdot \mathrm{F}}{\mathrm{R} \cdot \mathrm{T}} \cdot\left(\mathrm{E}-\mathrm{E}_{\mathrm{eq}}\right)\right]-\exp \left[-\frac{\alpha \cdot \mathrm{n} \cdot \mathrm{F}}{\mathrm{R} \cdot \mathrm{T}} \cdot\left(\mathrm{E}-\mathrm{E}_{\mathrm{eq}}\right)\right]\right\} \\
& \mathrm{i}: \text { current density, } \mathrm{A} / \mathrm{m}^{2} \\
& \mathrm{i}_{0}: \text { exchange current density, } \mathrm{A} / \mathrm{m}^{2} \\
& \mathrm{E}: \text { (corrosion) potential, } \mathrm{V} \\
& \mathrm{E}_{\text {eq }}: \text { equilibrium potential, } \mathrm{V} \\
& \mathrm{F}: \text { Faraday constant, Coulombs/mol } \\
& \mathrm{n}: \text { number of electrons involved in an electrodic reaction } \\
& \mathrm{R}: \text { universal gas constant, } \mathrm{J} /(\mathrm{mol} \mathrm{K}) \\
& \mathrm{T}: \text { absolute temperature, } \mathrm{K} \\
& \text { a: symmetry factor, dimensionless }
\end{aligned}
$$

The exchange current density $\mathrm{i}_{0}$ in the Butler-Volmer equation for the BCSR reaction is defined as the biofilm aggressiveness. This is an electrochemical parameter equivalent to the rate constant in conventional chemical reaction kinetics. Without biofilm catalysis, $\mathrm{i}_{0}$ for suflate reduction would be extremely small, meaning the reaction is kinetically retarded and will not proceed at any appreciable speed due to a high activation energy barrier. An SRB biofilm can greatly increase this parameter by lowering the activation energy. This parameter represents the catalytic ability of a biofilm to help remove electrons from an iron surface for utilization in biofilm anaerobic respiration. Analogously, if the potentials involved in the redox reaction consisting of Reactions (1) and (2) were pressures in a pressure-driven water flow system, the role of SRB biofilm catalysis would be analogous to de-blocking the pipe to allow flow to proceed. The exchange current density for the biofilm may vary with many parameters such as sessile cell density directly on the iron surface, their enzyme activities at different temperatures, the type of steel, and the type of iron sulfide film present on the iron surface. It is calibrated from SRB pitting data using a software program based on the BCSR model [11].
The classic electrochemical kinetics theory dictates that the anodic current density should equal to the overall cathodic current density that covers proton reduction, HAc reduction and sulfate reduction as shown in Eq. (10) in which $i_{a(\mathrm{Fe})}$ is calculated from Equation (9) without mass transfer resistance,

$$
\mathrm{i}_{\mathrm{a}(\mathrm{Fe})}=\mathrm{i}_{\mathrm{c}\left(\mathrm{H}^{+}\right)}+\mathrm{i}_{\mathrm{c}(\text { acetic_acid })}+\mathrm{i}_{{\mathrm{c}\left(\mathrm{SO}_{4}^{2-}\right)}}
$$

The cathodic current density for sulfate in the equation above is related to the cathodic charge transfer current density that is calculated from the Butler-Volmer equation and the cathodic mass transfer current density as shown below according to the classical electrochemical kinetics frequently used in mechanistic $\mathrm{CO}_{2}$ corrosion modeling [29],

$$
\frac{1}{\mathrm{i}_{\mathrm{c}\left(\mathrm{SO}_{4}^{2-}\right)}}=\frac{1}{\mathrm{i}_{\lim \left(\mathrm{SO}_{4}^{2-}\right)}}+\frac{1}{\mathrm{i}_{\mathrm{ct}\left(\mathrm{SO}_{4}^{2-}\right)}}
$$

The ratio of the two terms on the right hand side of Equation (11) is the mass transfer resistance to charge transfer resistance. As a pit grows, this ratio becomes larger because the distance for sulfate diffusion increases. For deep pits, mass transfer resistance dominates because sulfate in the bulk fluid must diffuse through a long distance to reach the pit bottoms. The following equation can be used to describe mass transfer of sulfate across a biofilm,

$$
\frac{\partial \mathrm{C}}{\partial \mathrm{t}}=\frac{\partial}{\partial \mathrm{x}}\left(\mathrm{D} \frac{\partial \mathrm{C}}{\partial \mathrm{x}}\right)+\mathrm{R}_{\mathrm{c}}
$$

C: concentration of a chemical species in biofilm, $\mathrm{mol} / \mathrm{m}^{3}$

$$
\text { D: sulfate diffusion coefficient in biofilm, } \mathrm{m}^{2} / \mathrm{s}
$$

$\mathrm{R}_{\mathrm{c}}$ : rate of consumption of sulfate by sessile SRB cells in the bulk of biofilm, $\mathrm{mol} /\left(\mathrm{m}^{3} \cdot \mathrm{s}\right)$

$\mathrm{R}_{\mathrm{c}}$ is a negative value for consumption of sulfate by the bulk sessile $\mathrm{SRB}$ cells in the biofilm. This consumption requires organic carbon as electron donor, because electrons from iron oxidation can only reach the sessile cells near the iron surface (often a monolayer of cells only) and they cannot "swim" to the bulk of the biofilm. The mass transfer current density is obtained from the following equation from the sulfate concentration gradient on the iron surface,

$$
\mathrm{i}_{\lim \left(\mathrm{SO}_{4}^{2-}\right)}=-\mathrm{nFD} \frac{\partial \mathrm{C}}{\partial \mathrm{x}}
$$

In the equation above, $\mathrm{n}$ equals to 8 because the reduction of each sulfate ion consumes 8 electrons. $\mathrm{i}_{\mathrm{a}(\mathrm{Fe})}$ obtained from Equation (10) can be converted to corrosion rate $\mathrm{CR}$ (pitting corrosion rate in this 1-D model) based on the following mass balance equation [11],

$$
\mathrm{CR}=\frac{\mathrm{M}_{\mathrm{Fe}}}{2 \mathrm{~F} \rho_{\mathrm{Fe}}} \mathrm{i}_{\mathrm{a}(\mathrm{Fe})}
$$
[30],

For typical iron and mild carbon steel, Equation (14) simplifies to

$$
\mathrm{CR}(\mathrm{mm} / \mathrm{y})=1.155 \mathrm{i}_{\mathrm{a}(\mathrm{Fe})}\left(\mathrm{A} / \mathrm{m}^{2}\right)
$$

Compared with SRB MIC investigations, APB MIC studies are lacking and there are no published correlations to calculate the $\mathrm{pH}$ and HAc concentration underneath biofilms. The HAc corrosion mechanism in this work is a simplistic one without consideration for the $\mathrm{CO}_{2}$ involvement [31] and scale or film formation that may inhibit HAc corrosion. Instead of modeling the mass transfer and acid production within the biofilm that require many unavailable parameter values, it is assumed that a constant acidic $\mathrm{pH}$ and a constant free HAc 
concentration at the bottom of a pit are maintained. Doing so requires that diffusion of proton and diffusion of HAc within the biofilm are sufficiently fast to accommodate their reduction reactions on the iron surface. Thus, mass transfer resistances of proton and HAc are not considered in the model. It also requires that the metabolic activities of the biofilm should be sufficiently fast to provide the protons and HAc molecules to sustain the specified local $\mathrm{pH}$ and acetic acid concentration, and to compensate for the loss due to diffusion into the bulk fluid. This again requires that there is sufficient organic carbon as food for the biofilm to produce the organic acids. Thauer et al. [19] mentioned that the prevailing hydrogen partial pressure is between 1 to $10 \mathrm{~Pa}$ in sediments. However, with significant proton reduction and HAc reduction locally, hydrogen partial pressure could be much higher. There is also a possibility that some hydrogen may be consumed by SRB or methanogens in the biofilm. Due to a lack of literature and lab data on the local hydrogen partial pressure on the iron surface, 1 bar is assumed in the Nernst equation for proton reduction potential calculation. A lower hydrogen pressure would result in a more positive $\mathrm{E}_{\mathrm{eq}}$ for proton reduction that means a larger driving force for corrosion. In practice, calibration using pitting data can help offset errors caused by the assumptions.

\section{Results and Discussion}

The extended BCSR model with proton and HAc reductions was solved numerically in the MIC prediction software known as MICORP Version 1.5.1 developed by the author. Figure 1 shows that corrosion potential $\mathrm{E}_{\text {corr }}$ is obtained from the intersection point of the anodic reaction curve (for iron oxidation) and the total cathodic reaction curve. There are three cathodic reactions, namely sulfate reduction, proton reduction and HAc reduction, each contributing to the total cathodic reaction curve to a different degree depending on their concentrations and other simulation parameters. The contributions do not linearly add up to the total cathodic reaction curve due the nonlinear nature of the model system. The intersection point yields the current density for corrosion current density $i_{\text {corr }}$. It is equal to $i_{a(F e)}$, which is used in Equation (15) to calculate the pitting corrosion rate in the 1-D model. Figure 2 shows that with $400 \mathrm{ppm}(\mathrm{w} / \mathrm{w})(4.17 \mathrm{mM})$ sulfate in the bulk-fluid phase and no free HAc at pit bottom $(\mathrm{pH} 7)$ at $45^{\circ} \mathrm{C}$, the maximum predicted pitting corrosion rate is around $3.3 \mathrm{~mm} /$ year even with an extremely large SRB biofilm aggressiveness $\left(\log _{10}\right.$ scale) of -6 . The upper end laboratory strain SRB biofilm aggressiveness for SRB is around -12 corresponding to a pitting corrosion rate of $1.4 \mathrm{~mm} /$ year at $28 \mathrm{mM}$ sulfate (typical seawater).

In Figure 2, when the aggressiveness increased beyond -8, pitting did not increase much. This was because mass transfer of sulfate was limited due to a relatively low sulfate concentration above the SRB biofilm in the bulk-fluid phase. As a pit grew, the distance for sulfate in the bulk fluid to diffuse to the bottom of the pit increased and this further reduced the ability of the biofilm to oxidize iron at the pit bottom. Figure 3 shows that mass transfer resistance became increasingly dominating over time as the pit grew deeper. In Figure 3, the sulfate consumption by the bulk sessile SRB cells with concomitant organic carbon oxidation was not considered in the simulation. If it had been considered, there would be less sulfate that reached the iron surface, meaning the corrosion rate due to BCSR could be even smaller. A sulfate diffusivity of $1.2 \times 10^{-9} \mathrm{~m}^{2} / \mathrm{s}$ in the biofilm at $45^{\circ} \mathrm{C}$ was used in the simulation in this work. It was calculated from the $0.7 \times 10^{-9}$ $\mathrm{m}^{2} / \mathrm{s}$ diffusivity value for sulfate in the biofilm at $25^{\circ} \mathrm{C}$ based on the Stokes-Einstein equation that says diffusivity is directly proportional to absolute temperature and inversely proportional to liquid viscosity [32]. The sulfate diffusivity in water is $1.06 \times 10^{-9} \mathrm{~m}^{2} / \mathrm{s}$ at $25^{\circ} \mathrm{C}$ according to Stewart [33]. The $0.7 \times 10^{-9} \mathrm{~m}^{2} / \mathrm{s}$ sulfate diffusivity value in the biofilm reflects a $34 \%$ discount. The discount depends on the biofilm density [11] that is not easily available.

Figure 4 shows that when a pit bottom $\mathrm{pH}$ of 3.6 is maintained, the one-year pit depth was slightly greater than $10 \mathrm{~mm}$. The corresponding free HAc concentration [HAc] was $226.3 \mathrm{ppm}\left(3.77 \times 10^{-3} \mathrm{M}\right)$ calculated from Equation (5) with $\mathrm{K}_{\mathrm{a}}=1.68 \times 10^{-5} \mathrm{M}$ at $45^{\circ} \mathrm{C}$ by assuming [Ac] $=$ $\left[\mathrm{H}^{+}\right]=2.51 \times 10^{-4} \mathrm{M}$, or $\left[\mathrm{Ac}^{-}\right]=14.8 \mathrm{ppm}$. This depth remained unchanged when the biofilm aggressiveness was less than or equal to -10 . This means that the contribution from the BCSR effect was negligible compared to HAc corrosion and proton corrosion. At $\mathrm{pH} 3.6,\left[\mathrm{H}^{+}\right]=$ $2.51 \times 10^{-4} \mathrm{M}$, that was 15 times smaller than $[\mathrm{HAc}]=3.77 \times 10^{-3} \mathrm{M}$. The

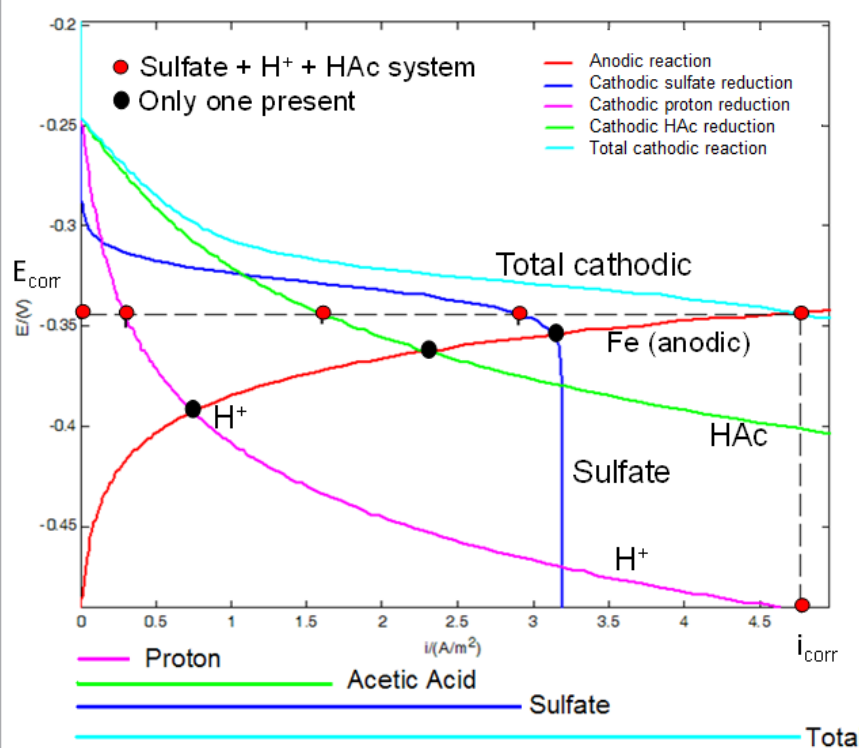

Figure 1: A simulation example to illustrate contributions from proton reduction, $\mathrm{HAC}$ reduction and sulfate reduction.

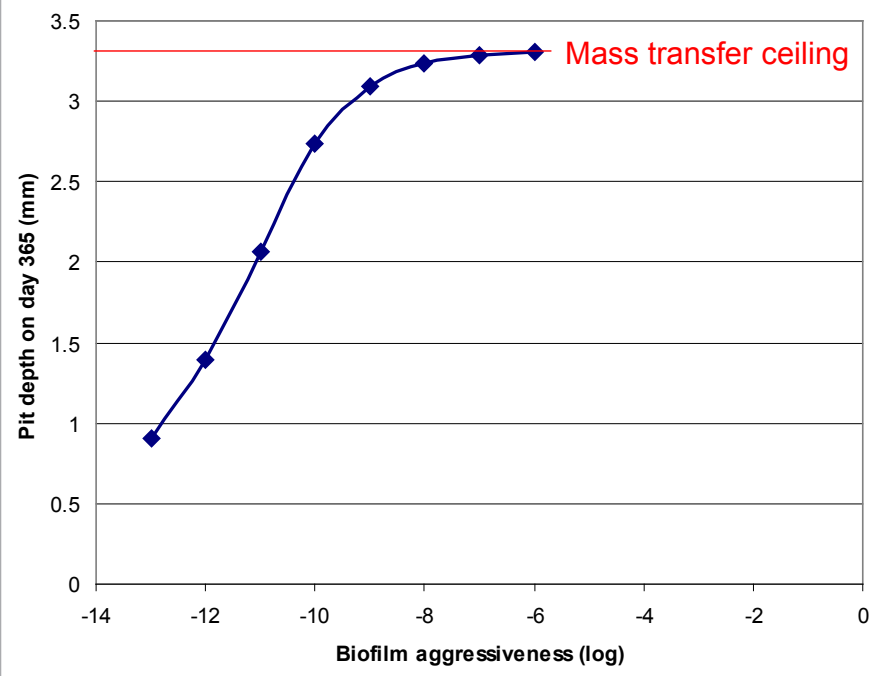

Figure 2: Simulation results based on $400 \mathrm{ppm}$ (4.17 mM) sulfate, $\mathrm{pH} 7$ and an initial SRB biofilm thickness of $0.1 \mathrm{~mm}$ at $45^{\circ} \mathrm{C}$ 


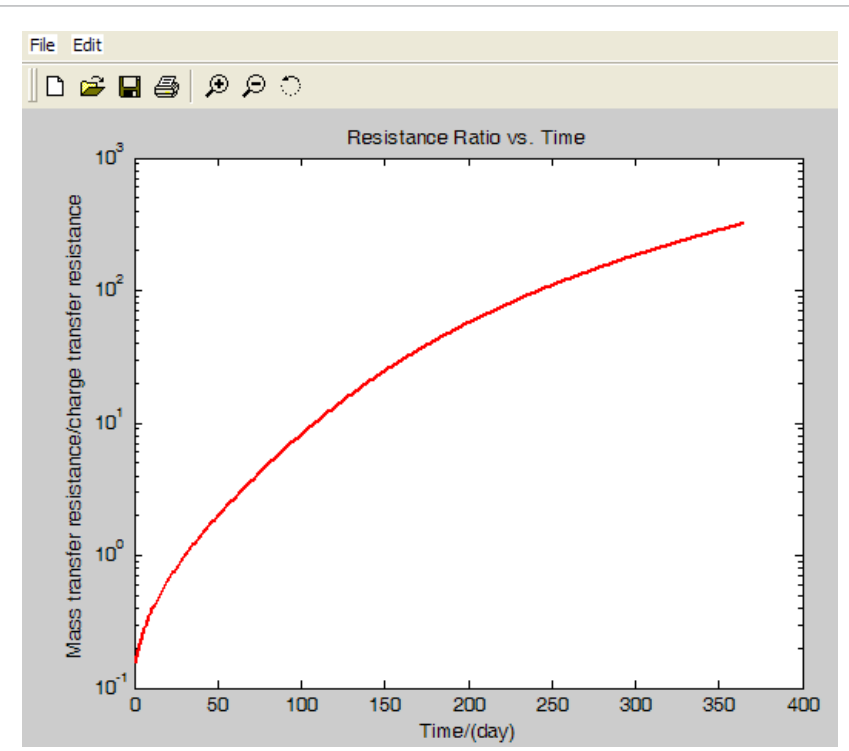

Figure 3: Simulated data (corresponding to Figure 1 with a fixed biofilm aggressiveness of -9 ) showing mass transfer resistance domination as pit grows deeper.

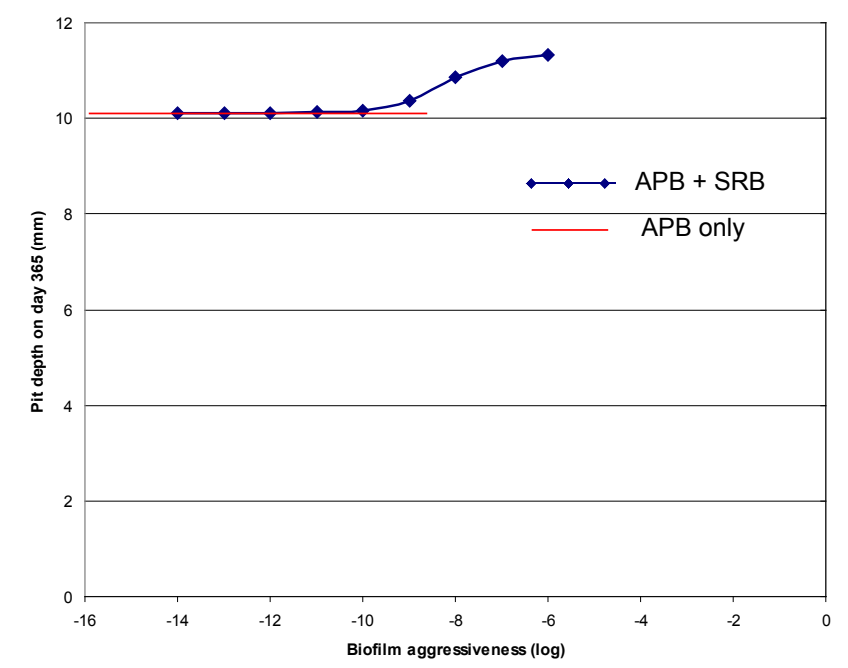

Figure 4: Model predicted pit depths for $\mathrm{pH} 3.6,226.3 \mathrm{ppm}$ free HAc, $400 \mathrm{ppm}$ sulfate and an initial SRB biofilm thickness of $100 \mu \mathrm{m}$ at $45^{\circ} \mathrm{C}$.

contributions from $\mathrm{HAc}$ and $\mathrm{H}^{+}$to the total corrosion rate remained roughly $94.5 \%$ and $5.5 \%$, respectively during the 365 days based on the cathodic current density values (see Equation (10)) calculated by the MIC software. The ratio of the two percentages was 17.2, not too far from the ratio of HAc and proton concentrations in this case. The simulation results indicated that HAc was far more corrosive than proton because $[\mathrm{HAc}]$ was much larger than $\left[\mathrm{H}^{+}\right]$. This is characteristic of organic acid corrosion that involves weak acids.

\section{Conclusions}

A mechanistic MIC model involving sulfate, proton and HAc reductions was used to prove that BCSR by SRB under a low sulfate concentration condition could not account for a very fast pitting corrosion rate, while APB corrosion with a sufficiently low pit bottom $\mathrm{pH}$ could. Based on the HAc corrosion theory and published field cases, it is reasonable to believe that severe APB attacks can lead to pipeline failures in less than a year if constant water wetting is an operating condition. As water-flooding is increasingly used to increase well pressure, water-wetting condition for an oil transport pipeline is becoming more common than ever. Alarmingly fast MIC pitting by $\mathrm{APB}$ can be a realistic threat in water-injection pipelines and waterwetted oil transport pipelines. The parameters in the modeling of proton and acetic acid attacks in this work can be refined by calibration using experimental and field data to predict local $\mathrm{pH}$ and HAc concentration more accurately corresponding to a pitting corrosion rate, or vice versa. It is desirable to obtain lab and field data for validation of the model observations. This work is a theoretical study to encourage a thrust in the experimental investigation and more accurate mechanistic modeling of MIC by APB. It calls for the awareness of potentially very fast pitting by APB. Attentions should also be paid to NRB MIC because it involves a much larger thermodynamic driving force.

This article is based on CORROSION/2012 conference paper no. C2012-000121 with permission from NACE International, Houston, Texas, USA.

\section{References}

1. Jacobson GA (2007) Corrosion at Prudhoe Bay: A lesson on the line. Mater Perform 46: 26-34

2. Videla HA, Herrera LK (2005) Microbiologically influenced corrosion: looking to the future. Int Microbiol 8: 169-180.

3. Hardy S (2004) Human microbiology, Psychology Press, Hove, United Kingdom.

4. Bhat S, Kumar B, Prasad SR, and Katarki MV (2011) Failure of a New 8-in Pipeline from Group Gathering Station to Central Tank Farm. Mater Perform 50: $50-54$.

5. Samant AK, Sharma VK, Thomas S, Anto PF, and Singh SK (1999) Investigation of Premature Failure of a Well Fluid Pipeline in an Indian Offshore Installation. In Advances in Corrosion Control and Materials in Oil and Gas Production Papers from EUROCORR '97 and EUROCORR '98, P.S. Jackman and L.M. Smith (eds.), (London: IOM Communications Ltd., 1999) 180-187.

6. DuBose BW, Fortnum RT, and Strickland NW (1996) A case history of microbiologically influenced corrosion in the Lost Hills oilfield, Kern County, California. Corrosion/1996 Paper No. 96297, NACE International, Houston, TX USA.

7. Shuler ML, Kargi F (2002) Bioprocess engineering, Prentice Hall, New York USA.

8. Xu D, Gu T (2011) Bioenergetics explains when and why more severe MIC pitting by SRB can occur. Corrosion/2011 Paper No. 11426, NACE International, Houston, TX, USA.

9. Vroom JM, De Grauw KJ, Gerritsen HC, Bradshaw DJ, Marsh PD, et al. (1999) Depth penetration and detection of $\mathrm{pH}$ gradients in biofilms by two-photon excitation microscopy. Appl Environ Microbiol 65: 3502-3511.

10. Pope DH (1988) Organic acid corrosion of carbon steel: a mechanism of microbiologically influenced corrosion. Corrosion/1999 Paper No. 8879, NACE International, Houston, TX, USA.

11. Gu T, Zhao K, Nesic S (2009) A practical mechanistic model for MIC based on a Biocatalytic Cathodic Sulfate Reduction (BCSR) theory. Corrosion/2009 Paper No. 09390, NACE International, Houston, TX, USA.

12. Pereira IA, Haveman SA, and Voordouw G (2007) Biochemical, genetic and genomic characterization of anaerobic electron transport pathways in sulphatereducing delta-proteobacteria. In Barton, L.L, Hamilton, W.A. (Eds.), SulphateReducing Bacteria: Environmental and Engineered Systems, pp. 215-240. Cambridge, UK: Cambridge University Press.

13. Gu T (2012) New Understandings of Biocorrosion Mechanisms and Their Classifications. J Microb Biochem Technol 4: iii-vi.

14. Sharma M, Aryal N, Sarma PM, Vanbroekhoven K, Lal B, et al. (2013) Bioelectrocatalyzed reduction of acetic and butyric acids via direct electron 
Citation: Gu T (2014) Theoretical Modeling of the Possibility of Acid Producing Bacteria Causing Fast Pitting Bioc'orrosion. J Microb Biochem Technol 6: 068-074. doi:10.4172/1948-5948.1000124

transfer by a mixed culture of sulfate-reducers drives electrosynthesis of alcohols and acetone. Chem Commun 49: 6495-6497.

15. Dominguez-Benetton X, Sevda S, Vanbroekhoven K, Pant D (2012) The accurate use of impedance analysis for the study of microbial electrochemical systems. Chem Soc Rev 41: 7228-7246.

16. Zhou M, Wang H, Hassett DJ, and Gu T (2013) Recent advances in Microbial Fuel Cells (MFCs) and Microbial Electrolysis Cells (MECs) for wastewater treatment, bioenergy and bioproducts. J Chem Technol Biotechnol 88: 508518.

17. von Wolzogen Kuehr CAH, van der Vlugt LS (1934) The graphitization, of cast iron as an electrochemical process in anaerobic soils. Water 18: 147-165.

18. Boronstein SW (1994) Microbiologically Influenced Corrosion Handbook, Industrial Press, New York, USA.

19. Thauer RK, Stackebrandt E, Hamilton WA (2007) Energy metabolism phylogenetic diversity of sulphate-reducing bacteria. In Barton, L.L., Hamilton, W.A., (Eds.), Sulphate-Reducing Bacteria: Environmental and Engineered Systems, pp 1-37, Cambridge, UK: Cambridge University Press.

20. King RA, Miller JDA (1971) Corrosion by the Sulphate-reducing Bacteria. Nature 233: 491-492.

21. Peck HD (1993) Bioenergetic strategies of the sulfate-reducing bacteria In Chapter 3 of J.M. Odom, R. Singleton, Jr. (Eds.), The Sulfate-Reducing Bacteria: Contemporary Perspectives, pp. 41-76, Springer-Verlag, Berlin-New York, USA.

22. Xu D, Li Y, Fengmei Song, Gu T (2013) Laboratory Investigation of Microbiologically Influenced Corrosion of C1018 Carbon Steel by Nitrate Reducing Bacterium Bacillus licheniformis. Corros Sci 77: 385-390.

23. Chan KY, Xu LC, Fang HHP (2002) Anaerobic electrochemical corrosion of mild steel in the presence of extracellular polymeric substances produced by a culture enriched in sulfate-reducing bacteria. Environ Sci Technol 36: 17201727.
24. Boivin J, Bryant R, Laishley EM, Costerton JW (1990) Influence of Enzyme Systems on Microbiologically Influenced Corrosion. Corrosion/1990 Paper No. 128, NACE International, Houston, TX, USA.

25. George K, de Waard K, Nesic S (2004) Electrochemical investigation and modeling of carbon dioxide corrosion of carbon steel in the presence of acetic acid. Corrosion/2004 Paper No. 04379, NACE International, Houston, TX, USA.

26. Nordsveen M, Nesic S, Nyborg R, Stangeland A (2003) A mechanistic model for carbon dioxide corrosion of mild steel in the presence of protective iron carbonate films-Part 1: Theory and verification. Corrosion 59: 443-456.

27. George KS, Nesic S (2007) Investigation of carbon dioxide corrosion of mild steel in the presence of acetic acid-Part 1: Basic mechanisms. Corrosion 63 178-186.

28. Garsany $Y$, Pletcher D, Hedges BM (2002) The Role of Acetate in CO Corrosion of carbon steel: Has the Chemistry been forgotten? Corrosion/2002 Paper No. 02273, NACE International, Houston, TX, USA.

29. Nesic S, Postlethwaite J, Olsen S (1996) An electrochemical model for prediction of corrosion of mild steel in aqueous carbon dioxide solutions. Corrosion 52: 280-294.

30. Sun W, Srdjan N (2006) Kinetics of iron carbonate and iron sulfide scale formation in $\mathrm{CO}_{2} / \mathrm{H}_{2} \mathrm{~S}$ corrosion, $\mathrm{PhD}$ thesis, Ohio University, Athens, Ohio, USA.

31. Crolet JL, Dugstad AL, Thevenot NL (1999) Role of free acetic acid on the CO2 corrosion of steels. Corrosion/1999 Paper No. 24, NACE International, Houston, TX, USA

32. Geankoplis C (2003) Transport processes and separation process principles (includes unit operations), 4th edition, Prentice Hall Press, Upper Saddle River, NJ, USA.

33. Stewart PS (2003) Diffusion in biofilms. J Bacteriol 185: 1485-1491. 